\title{
Deposition Time and Thermal Cycles of Fabricating Thin-wall Steel Parts by Double Electrode GMAW Based Additive Manufacturing
}

\author{
Dongqing Yang ${ }^{1}$ and Guangjun Zhang ${ }^{\mathrm{a}, 1}$ \\ ${ }^{1}$ State Key Laboratory of Advanced Welding and Joining, Harbin Institute of Technology, Harbin 150001, China;
}

\begin{abstract}
The deposition time for fabricating the thin-wall part as well as the peak temperature of the substrate during the process was analyzed in the double electrode gas metal arc welding (DE-GMAW) based additive manufacturing (AM). The total deposition time and the interlayer idle time of the manufacturing process decreased with the increasing of the bypass current under the same interlayer temperature and the same deposition rate. The thermal cycling curves illustrated that the peak temperature of the substrate was lower in the DE-GMAW base AM under the same conditions. When depositing the thin-wall parts, the DE-GMAW based AM can reduce the heat input to the substrate and improve the fabrication efficiency, compared with the GMAW based AM.
\end{abstract}

\section{Introduction}

Additive manufacturing (AM) is an advanced fabrication technique that can make parts through a layer by layer deposition based on the virtual solid models. Due to its considerable reductions in production costs and savings of materials, AM has become a hotspot of research in the worldwide [1]. Especially, with the increasing requirement for the industrial technologies, fabricating metallic functional products by additive manufacturing has attracted the attention of many researchers over the recent years [2]. According to the heat source utilized in the deposition process, metallic components AM technologies can be divided into following three categories mainly: laser, electron beam and welding arc. The equipment expenditure and maintenance costs were high in laser and electron beam based AM. In contrast, the welding arc based AM has the advantages of the simpler equipments and low production cost [3]. Moreover, the metal wire was employed as the deposited raw materials in mostly welding arc based AM, thus it was a cleaner technique with fewer contamination issues, compared with the process using powder [4]. Based on the different welding processes using in AM, it can be classified into following categories: gas metal arc welding (GMAW), gas tungsten arc welding (GTAW), and plasma arc welding (PAW). In GTAW and PAW based AM, the wire was fed into the molten pool individually and the arc was ignited between the tungsten and the base metal. But in GMAW based AM, the welding arc was directly struck between the wire and the substrate. In this condition, the electric arc will melt the wire quickly and it will lead to high deposition rate in GMAW base AM. Thus, GMAW based AM is more suitable for fabricating the medium and large scale structure metal parts [5].

\footnotetext{
${ }^{\mathrm{a}}$ Corresponding author : zhanggj@hit.edu.cn
} 
A number of investigations about the GMAW-based AM have been explored recently [6-10]. However, during the traditional researches on GMAW-based AM, the heat accumulation in the deposition is a common problem that restricts the development and application of GMAW based AM technique. The usual measures to solve this problem are decreasing the wire melting current, increasing travel speed or delaying the time between two adjacent layered depositions. Those will lead to lower deposition rate and weaken the advantages of this technique. Taking a page from the welding field, the double electrode gas metal arc welding (DE-GMAW) technique proposed by Zhang et al. and improved by $\mathrm{Li}$ et al. was characterized by reducing the heat input into the substrate through the bypass arc under the same deposition rate [11-12]. It was introduced into the weld-based additive manufacturing in our previous research [13]. The forming characteristics in multi-layer single-bead additive manufacturing by DE-GMAW were investigated and the effect of the bypass current on the deposition quality was illustrated in that work. Based on it, this paper aims at analyzing the thermal behavior of the DE-GMAW based AM process by the measurement of the thermal cycles and investigating the effect of the bypass arc on the deposition time and the thermal cycles.

\section{Experimental procedure}

The DE-GMAW based additive manufacturing system is shown in Fig. 1. DE-GMAW was established by introducing a GTAW torch to form a second current loop for the wire melting current. In that way, the base metal current was decoupled from the melting current and heat input to the base metal was lower. In this work, the Panasonic YD-500FR welding machine with constant voltage mode was the GMAW power supply and the Rilon WS-400 with constant current mode was the bypass arc power supply. The computer can achieve the following functions: controlling the movement of the work flat, on/off control of GMAW and GTAW, adjustment of relative process parameters, and collecting and recording the data of the thermal cycles during the deposition. In this work, both welding torches were always static as shown in Fig. 1 and the thin-wall part was fabricated with the descending of the work flat. The H08Mn2Si steel wire with $1.2 \mathrm{~mm}$ diameter was served as consumable material deposited on the Q235 low carbon steel plates with dimension of $250 \mathrm{~mm} \times 80 \mathrm{~mm} \times 9.5 \mathrm{~mm}$. The diameter of the tungsten electrode used in the GTAW torch was $3.2 \mathrm{~mm}$. The shielding gas for GMAW torch was $\mathrm{Ar}(95 \%)$ and $\mathrm{CO}_{2}(5 \%)$ gas mixture with a constant flow rate of $15 \mathrm{~L} / \mathrm{min}$ and the pure Ar gas was supplied for the GTAW torch with $8 \mathrm{~L} / \mathrm{min}$ flow rate. The relative position of two welding torches was just same with Ref. [13].

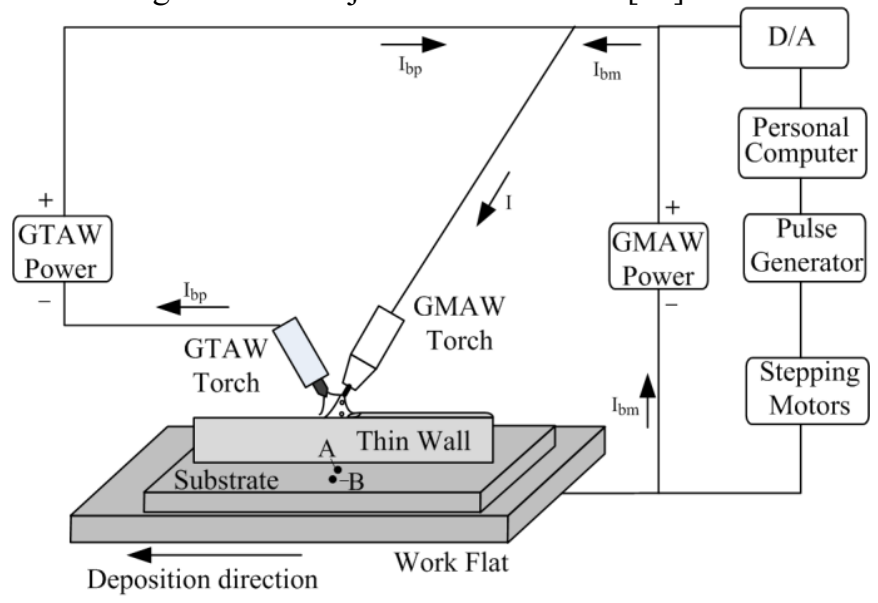

Figure 1. Schematic diagram of DE-GMAW based AM system.

For this research, the deposition time and thermal behavior of the DE-GMAW based additive manufacturing are key points. Based on the previous researches, we have conducted some groups of experiments with depositing thin-wall parts. As illustrated in Tab.1, the experimental parameters were 
listed in detail. In the experiment $1-4$, the every layer has been deposited $180 \mathrm{~mm}$ length and the interpass temperature of the deposited parts was controlled at $70^{\circ} \mathrm{C}$ measured in the middle of the top surface by an infrared thermometer. The interval time and the total deposition time were recorded. In the experiment 5-6, the thermal cycling data of the deposition process has been collected, the deposited length of every layer was $150 \mathrm{~mm}$, and the interpass temperature was $60^{\circ} \mathrm{C}$. The thermal cycling curves on substrate were measured by some thermocouples (K type) distributing at points $\mathrm{A}$ and B on the top surface of substrate as shown in Fig.1. The distance from Point A to the center line of the parts was $15 \mathrm{~mm}$ and the Point B was $30 \mathrm{~mm}$ away from the center.

Table 1. Experimental condition of DE-GMAW based AM.

\begin{tabular}{|c|c|c|c|c|c|}
\hline No. & $\begin{array}{c}\text { Wire feed speed } \\
(\mathbf{m} / \mathbf{m i n})\end{array}$ & $\begin{array}{c}\text { Bypass current } \\
(\mathbf{A})\end{array}$ & $\begin{array}{c}\text { Arc voltage } \\
(\mathbf{v})\end{array}$ & $\begin{array}{c}\text { Deposition velocity } \\
(\mathbf{m m} / \mathbf{s})\end{array}$ & $\begin{array}{c}\text { Total number of } \\
\text { layers }\end{array}$ \\
\hline 1 & 4.21 & 0 & 23 & 5 & 20 \\
\hline 2 & 4.21 & 40 & 23 & 5 & 20 \\
\hline 3 & 4.21 & 80 & 23 & 5 & 20 \\
\hline 4 & 4.21 & 120 & 23 & 5 & 20 \\
\hline 5 & 4.21 & 0 & 23 & 5 & 15 \\
\hline 6 & 4.21 & 80 & 23 & 5 & 15 \\
\hline
\end{tabular}

\section{Results and discussion}

\subsection{Deposition time}

In the Exp 1-4, except for the first layer, the other layers were deposited after the temperature of the previous layer metal dropping to $70^{\circ} \mathrm{C}$. Thus, there was an interval between the adjacent layers, namely interlayer idle time. The interlayer idle time of every layer deposition for cooling the parts with different bypass current was shown in Fig. 2. It is obvious that the idle time between the adjacent layers decreased with increase of the bypass current in general. It was due to the reduction in the heat input of the deposited part with the bypass arc. The higher bypass current caused more reduction of the heat input in DE-GMAW based AM. In each experiment, the time interval between the contiguous depositions was shortest between the first layer and second layer, then it was extended as the increasing of the deposition layer number, and finally it reached a certain value with small fluctuation. This was because the first layer deposition was closed to the cool substrate with good heat diffusion condition and the temperature of the metal layer dropped fast. With the increasing of deposition height, the heat diffusion condition was poor and the time interval for cooling the part was stretched and maintained stable eventually.

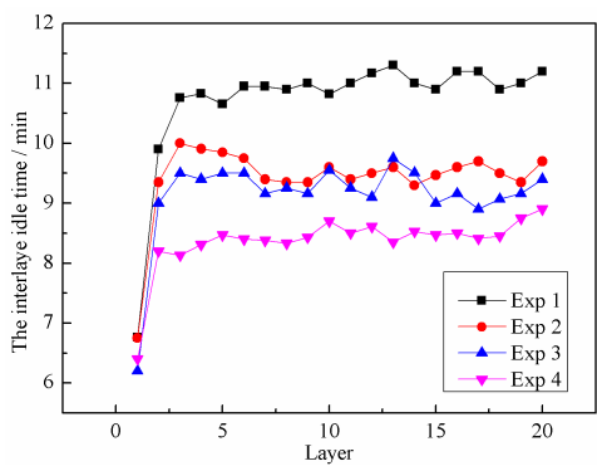

Figure 2. The interval time between the adjacent layers in the Exp 1-4. 
In Tab.2, the total deposition time, total interlayer idle time and mean interlayer idle time were listed. The total deposition time included the interlayer idle time and the actual deposition time. In Exp 1-4, the actual deposition time was always $12 \mathrm{~min}$ according to the calculation. Therefore, the total deposition time depended on the interlayer idle time of every layer deposition. As illustrated in Tab.2, the total interlayer idle time decreased with the increase of the bypass current. The maximum reduction of the total deposition can reach $21 \%$ with the bypass current of $120 \mathrm{~A}$. The total volume of deposition metal was constant in theory due to the same wire feed speed, deposition velocity and deposition length in the Exp 1-4. The more the total deposition time, the lower the production efficiency. That is to say, the manufacturing efficiency during the DE-GMAW based AM was higher than the one of the GMAW based AM with the same conditions, taking no account of the deposition quality. In the Fig.3, the deposition time of different layer number was always shortened with the growth of the bypass current. The larger the layer number, the more the shortened time of the deposition in DE-GMAW based AM, compared with the GMAW based AM in the same deposition rate.

Table 2. The total deposition time in experiment 1-4.

\begin{tabular}{|c|c|c|c|}
\hline Experiment & $\begin{array}{c}\text { Total deposition time } \\
\text { (min) }\end{array}$ & $\begin{array}{c}\text { Total interlayer idle time } \\
\text { (min) }\end{array}$ & $\begin{array}{c}\text { Mean interlayer idle time } \\
\text { (min) }\end{array}$ \\
\hline 1 & 226.39 & 214.39 & 10.72 \\
\hline 2 & 200.43 & 188.43 & 9.42 \\
\hline 3 & 194.52 & 182.52 & 9.13 \\
\hline 4 & 179.22 & 167.22 & 8.36 \\
\hline
\end{tabular}

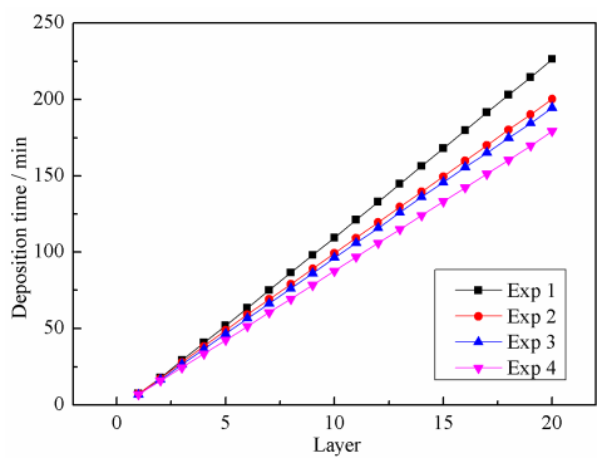

Figure 3. The deposition time with different layer numbers in Exp 1-4.

\subsection{Thermal cycling}

The thermal cycles on the substrate with different parameters have been acquired in the Exp 5-6. The typical thermal cycles were shown in Fig. 4 and the characteristics of the curves were obvious. Here just listed the thermal cycling curves of the point $\mathrm{A}$ and point $\mathrm{B}$ on the substrate. The welding arc as the heat source was applied on the parts 15 times in every experiment. Accordingly, the points of the substrate went through thermal cycling with 15 peaks in this condition. With the increase of layer number, the heat source was farther from the points on the substrate. As a result, the peak temperature of the points declined gradually. Meanwhile, the interlayer temperature of each layer was controlled at $60^{\circ} \mathrm{C}$ and the temperature of the point $\mathrm{A}$ on the substrate was slightly lower about $55^{\circ} \mathrm{C}$. The point $\mathrm{B}$ was farther away from the center of the part than the point $\mathrm{A}$ and the peak temperature was lower. The cooling curves of the thermal cycling were mainly synchronized in both points. 

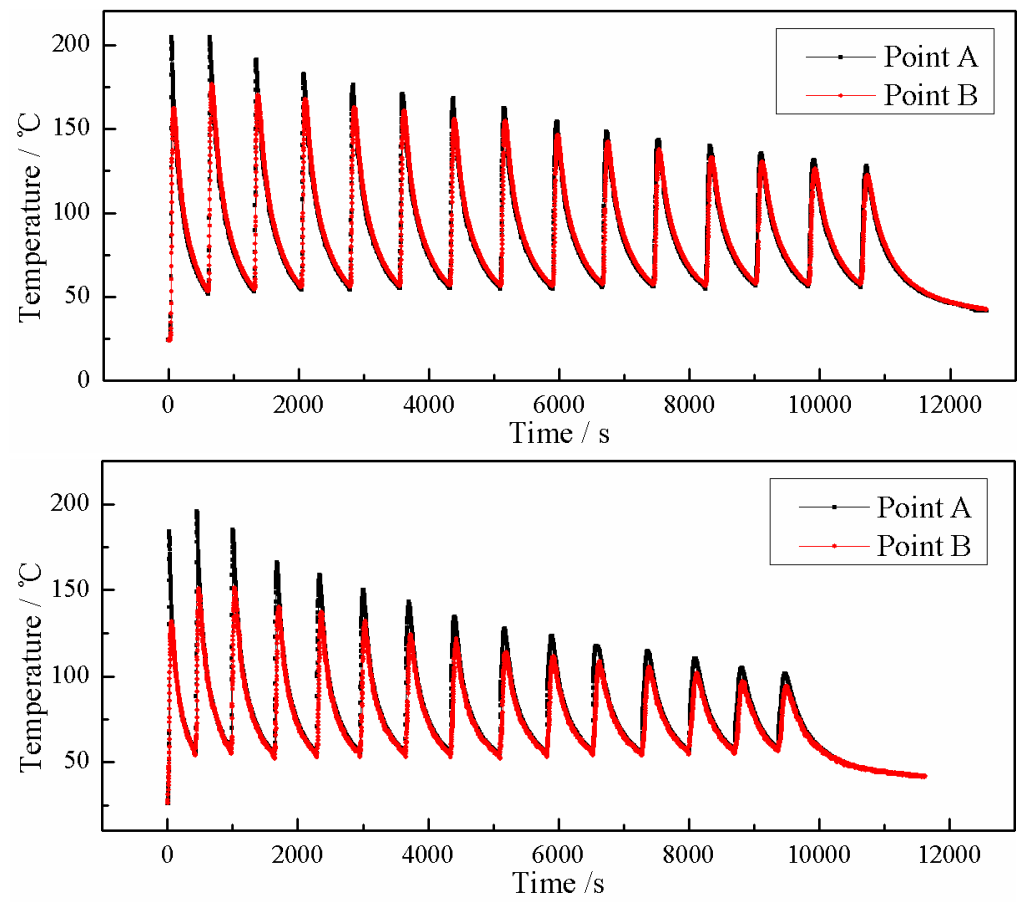

(a)

(b)

Figure 4. Thermal cycles of Point A and B in Experiment 5-6. (a) Exp 5. (b) Exp 6.

The effect of the bypass arc on the thermal cycles of the points on the substrate was distinct and can be seen in the Fig. 5. Thermal cycling curves of the points on the substrate were similar, except for the peak temperature. Thus, only the result of the point A was presented here. The peak temperature in Exp 5 of each layer deposition was higher than that with bypass current in Exp 6 . That means the heat input during the GMAW based AM is higher than that during the DE-GMAW based AM with suitable bypass current in the same deposition rate. The result of the total deposition time and interval idle time in different experiments was in accord with the content of Section 3.1.

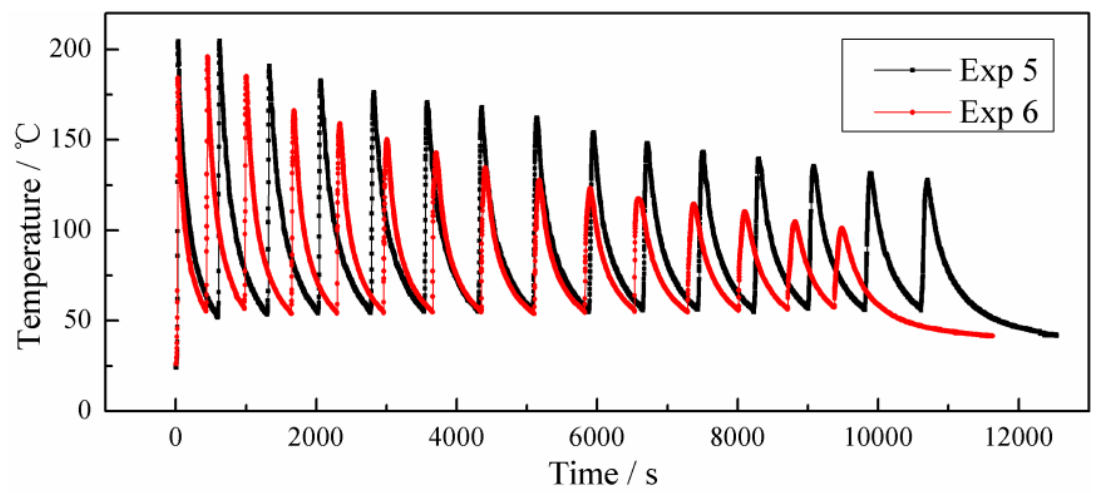

Figure 5. Comparison of thermal cycles of Point A in Exp 5 and Exp 6.

\section{Conclusions}

The total deposition time of fabricating the thin-wall part and the interval time decreased with the increasing of the bypass current under the same deposition rate during the DE-GMAW based AM. The peak temperature of the substrate during the deposition was lower in the DE-GMAW based AM 
compared with the one in GMAW based AM. When depositing the thin-wall parts, the DE-GMAW based AM can reduce the heat input to the substrate and improve the fabrication efficiency, compared with the GMAW based AM.

\section{References}

1. S.H. Huang, P. Liu, A. Mokasdar, L. Hou, Int. J. Adv. Manuf. Technol. 67, 1191-1203 (2013).

2. G. Tapia, A. Elwany, ASME J. Manuf. Sci. Eng. 136, 1-10 (2014).

3. B. Baufeld, E. Brandl, O. Biest, J. Mater. Process. Technol. 211, 1146-1158 (2011).

4. F. Martina, J. Mehnenb, S.W. Williams, P. Colegrove, F. Wanga, J. Mater. Process. Technol. 212, 1377-1386 (2012).

5. M.P. Mughal, H. Fawad, R.A. Mufti, Proc. Inst. Mech. Eng. Part C-J. Eng. Mech. Eng. Sci. 220, 875-885 (2006).

6. H. H. Zhao, G.J. Zhang, Z.Q. Yin, L. Wu, J. Mater. Process. Technol. 211, 488-495 (2011).

7. P.A. Colegrove, H.E. Coules, J. Fairman, F. Martina, T. Kashoob, H. Mamash, L.D Cozzolino, J. Mater. Process. Technol. 213, 1782-1791 (2013).

8. P. Kazanas, P. Deherkar, P. Almeida, H. Lockett, S. Williams, Proc. Inst. Mech. Eng. Part C-J. Eng. Manuf. 226, 1042-1051 (2012).

9. X.W. Bai, H.O. Zhang, G.L. Wang, Procedia CIRP. 6, 515-520 (2013).

10. J. Xiong, G.J. Zhang, Z.L. Qiu, Y.Z. Li, J. Clean. Prod. 41, 82-88 (2013).

11. Y.M. Zhang, M. Jiang, W. Lu, Weld. J. 83, 39-41 (2004).

12. K.H. Li, , J.S. Chen, Y.M. Zhang, Weld. J. 86, 231s-237s (2007).

13. D.Q. Yang, C.J. He, G.J. Zhang, J. Mater. Process. Technol. 227, 153-160 (2016). 